\title{
Qualidade de adesão das madeiras de Corymbia citriodora e Eucalyptus pellita tratadas termicamente
}

\author{
Adhesion quality of the heat treated Corymbia citriodora \\ and Eucalyptus pellita woods
}

\author{
Cintia Silva Nunes ${ }^{1}$, Alexandre Miguel do Nascimento ${ }^{2}$, \\ Rosilei Aparecida Garcia ${ }^{3}$ e Roberto Carlos Costa Lelis ${ }^{4}$
}

\begin{abstract}
Resumo
O tratamento térmico melhora a estabilidade dimensional e a durabilidade natural da madeira. Entretanto, ele também pode modificar as características físicas e químicas das superfícies da madeira, as quais afetam o desempenho dos adesivos e revestimentos. Os objetivos deste estudo foram avaliar o efeito do tratamento térmico e das suas modificações físicas e químicas na adesão de juntas coladas das madeiras de Corymbia citriodora e Eucalyptus pellita. O tratamento térmico foi realizado em um forno mufla elétrico laboratorial a 180 e $200^{\circ} \mathrm{C}$. Os ensaios de cisalhamento foram realizados segundo as normas ASTM D 905-94 e ASTM D 143-94. Foram utilizados três adesivos: resorcinol, resorcinol-tanino 80:20 e resorcinol-tanino 60:40. A resistência ao cisalhamento da madeira sólida e das juntas coladas foi severamente afetada pelos tratamentos. $O$ adesivo resorcinol-tanino 80:20 apresentou um desempenho melhor ou igual ao resorcinol. As juntas coladas das madeiras tratadas apresentaram uma alta porcentagem de falhas na madeira devido à perda de resistência, maior porosidade e maior penetração do adesivo. A acidez da madeira tratada afetou a resistência ao cisalhamento e apresentou uma forte correlação com o teor de umidade de equilíbrio. Os tratamentos a 180 e $200^{\circ} \mathrm{C}$ são extremamente severos para as madeiras de Corymbia citriodora e Eucalyptus pellita nas condições estudadas.
\end{abstract}

Palavras-chave: falha na madeira, porosidade, resistência ao cisalhamento, adesivo resorcinol-tanino.

\begin{abstract}
Heat treatment improves dimensional stability and natural durability of the wood. It can also modify the physical and chemical characteristics of wood surfaces, which affect the adhesive and coating performance. The objectives of this study were to evaluate the effect of the heat treatment and the physical and chemical modifications on adhesion of glued joints of the Corymbia citriodora and Eucalyptus pellita woods. Heat treatment was performed in a laboratory electric oven at 180 and $200^{\circ} \mathrm{C}$. Shear strength tests were performed according to ASTM D 905-94 and ASTM D 143-94 standards. Three adhesive were used: resorcinol, resorcinol-tannin 80:20 and resorcinol-tannin 60:40. The shear strength of solid wood and glued joints was severely affected by treatments. Resorcinol-tannin 80:20 adhesive had the best performance, equal to resorcinol. Glued joints of heat-treated woods showed a high percentage of wood failure due to strength loss, high porosity and adhesive penetration. The acidity of heat-treated woods affected the shear strength and presented a strong correlation with equilibrium moisture content. Heat treatments at 180 and $200^{\circ} \mathrm{C}$ were extremely severe to Corymbia citriodora and Eucalyptus pellita woods under the conditions studied.
\end{abstract}

Keywords: wood failure, porosity, shear strength, resorcinol-tannin adhesive.

\section{INTRODUÇÃO}

Nas últimas décadas, o tratamento térmico da madeira tem sido o foco de inúmeras pesquisas por agregar propriedades desejáveis tais como maior estabilidade dimensional e maior durabilidade natural. Entretanto, o tratamento térmico também pode alterar drasticamente as propriedades

\footnotetext{
${ }^{1}$ Engenheira Florestal, M.Sc. em Ciências Ambientais e Florestais. UFRRJ - Universidade Federal Rural do Rio de Janeiro / Instituto de Florestas. BR 465, km 07 - 23890-000 - Seropédica, RJ, Brasil. E-mail: cintianuness@yahoo.com.br

${ }^{2}$ Engenheiro Florestal, Doutor em Ciência Florestal. UFRRJ - Universidade Federal Rural do Rio de Janeiro / Instituto de Florestas, Departamento de Produtos Florestais. BR 465, km 07 - 23890-000 - Seropédica, RJ, Brasil. E-mail: amn@ufrrj.br ${ }^{3}$ Engenheira Florestal, Ph.D. em Ciências da Madeira. UFRRJ - Universidade Federal Rural do Rio de Janeiro / Instituto de Florestas, Departamento de Produtos Florestais. BR 465, km 07 - 23890-000 - Seropédica, RJ, Brasil. E-mail: rosileigar@hotmail.com

${ }^{4}$ Engenheiro Florestal, Doutor em Ciência Florestal. UFRRJ - Universidade Federal Rural do Rio de Janeiro / Instituto de Florestas, Departamento de Produtos Florestais - BR 465, km 07 - 23890-000 - Seropédica, RJ, Brasil. E-mail: lelis@ufrrj.br
}

Sci. For., Piracicaba, v. 44, n. 109, p. 41-56, mar. 2016 DOI: dx.doi.org/10.18671/scifor.v44n109.04 
físicas e químicas da superfície da madeira, as quais afetam a adesão e a aplicação de revestimentos (WILLIAMS, 2010). Além disso, a madeira tratada é menos higroscópica, o que pode alterar a distribuição e a penetração do adesivo (SERNEK et al., 2008). Segundo o FPL (2010), a secagem e o aquecimento da madeira deterioram as condições físicas e químicas de suas superfícies devido à migração dos extrativos, à reorientação das moléculas da superfície e do fechamento dos microporos das paredes celulares de forma irreversível. Desta forma, as superfícies das madeiras tratadas termicamente podem tornar-se quimicamente inativas à adesão devido à presença de contaminantes químicos e extrativos hidrofóbicos.

Para uma adesão efetiva, o adesivo deve penetrar na estrutura porosa da madeira, sendo a profundidade dependente do volume de vazios na madeira. Para atingir uma alta resistência das juntas, o adesivo deve penetrar e ancorar em uma profundidade de várias células em uma estrutura celular sólida e não danificada (FPL, 2010). Estudos realizados por Awoyemi e Jones (2011) mostram que o tratamento térmico degrada a parede celular e aumenta a sua porosidade.

As madeiras de Corymbia citriodora e Eucalyptus pellita apresentam altas densidades (DOMBRO, 2010; IPT, 1989) e teores de extrativos elevados (COSTA et al., 1997), que comprometem a penetração do adesivo. Além disso, espécies de altas densidades apresentam maior movimentação em serviço, ou seja, maior instabilidade dimensional, o que compromete a integridade da linha de cola ao longo do tempo (FPL, 2010; SERNEK et al., 2008). Sendo assim, madeiras mais estáveis proporcionariam um melhor desempenho ao adesivo devido ao menor estresse causado pela maior estabilidade dimensional.

Neste contexto, os objetivos deste estudo foram avaliar o efeito do tratamento térmico e das suas modificações físicas e químicas na adesão de juntas coladas das madeiras de Corymbia citriodora e Eucalyptus pellita.

\section{MATERIAL E MÉTODOS}

\section{Material e tratamento térmico}

O material utilizado foi obtido de seis árvores de Corymbia citriodora (Hook.) K. D. Hill \& L.A.S. Johnson e Eucalyptus pellita F. Muell com 17 anos de idade, provenientes de plantios localizados no campus da Universidade Federal Rural do Rio de Janeiro, Seropédica-RJ. Retirou-se uma tora de cada árvore na altura do DAP, as quais foram desdobradas em tábuas de 3,6 x 0,15 x 0,07 m (comprimento $\mathrm{x}$ largura $\mathrm{x}$ espessura) e secas ao ar livre, em local coberto a fim de evitar o contato direto com as intempéries. As tábuas foram empilhadas de tal maneira que permitisse a circulação de ar de forma homogênea entre as camadas da pilha visando diminuir os defeitos ao longo do processo de secagem. Foram selecionadas aleatoriamente 12 tábuas contendo somente cerne, das quais foram obtidas 150 amostras com dimensões de 400 x 60 x $28 \mathrm{~mm}$ (comprimento x largura x espessura) para cada espécie. As amostras foram acondicionadas em câmara climática a $20^{\circ} \mathrm{C}$ e $65 \%$ de umidade relativa (UR) até atingir o teor de umidade de equilíbrio.

O tratamento térmico foi realizado em um forno mufla elétrico laboratorial, da marca Linn Elektro Therm, com dimensões de 600 x 600 x $700 \mathrm{~mm}$, equipado com um sistema de controle de temperatura e tempo. A temperatura interna do forno mufla e das amostras foi monitorada por termopares conectados a um sistema de aquisição de dados composto pelos softwares AqDados 7.02.09 e AqDAnalysis Aq 0688. Para cada batelada de tratamento, foram introduzidas 12 amostras no interior do forno mufla, as quais foram empilhadas de maneira que permitisse a circulação do calor entre as peças.

O tratamento térmico foi realizado em quatro etapas, sendo selecionadas duas temperaturas: 180 e $200^{\circ} \mathrm{C}$. As quatro etapas do tratamento foram: (1) aquecimento das amostras até $100^{\circ} \mathrm{C}$ : período correspondente a 2 horas; (2) aumento da temperatura de $100^{\circ} \mathrm{C}$ até a temperatura final (180 ou $200^{\circ} \mathrm{C}$ ): período correspondente a 30 minutos; (3) tempo de tratamento na temperatura final: período correspondente a 1 hora e 30 minutos e 4) resfriamento do material durante aproximadamente 2 horas. A Figura 1 apresenta o ciclo total do tratamento térmico correspondente a 6 horas. As condições de temperatura e tempo dos tratamentos térmicos foram estipuladas após a realização de ensaios preliminares e a avaliação da qualidade das peças tratadas, ou seja, pela presença de 
defeitos. O teor de umidade inicial das amostras foi de aproximadamente 10-12\%. Após os tratamentos, as amostras foram acondicionadas em câmara climática a $20^{\circ} \mathrm{C}$ e $65 \%$ de UR até atingir o teor de umidade de equilíbrio. As amostras foram divididas em três grupos: controle (não tratadas) e tratadas a $180^{\circ} \mathrm{C}$ e $200^{\circ} \mathrm{C}$ com 50 amostras por grupo para cada espécie.

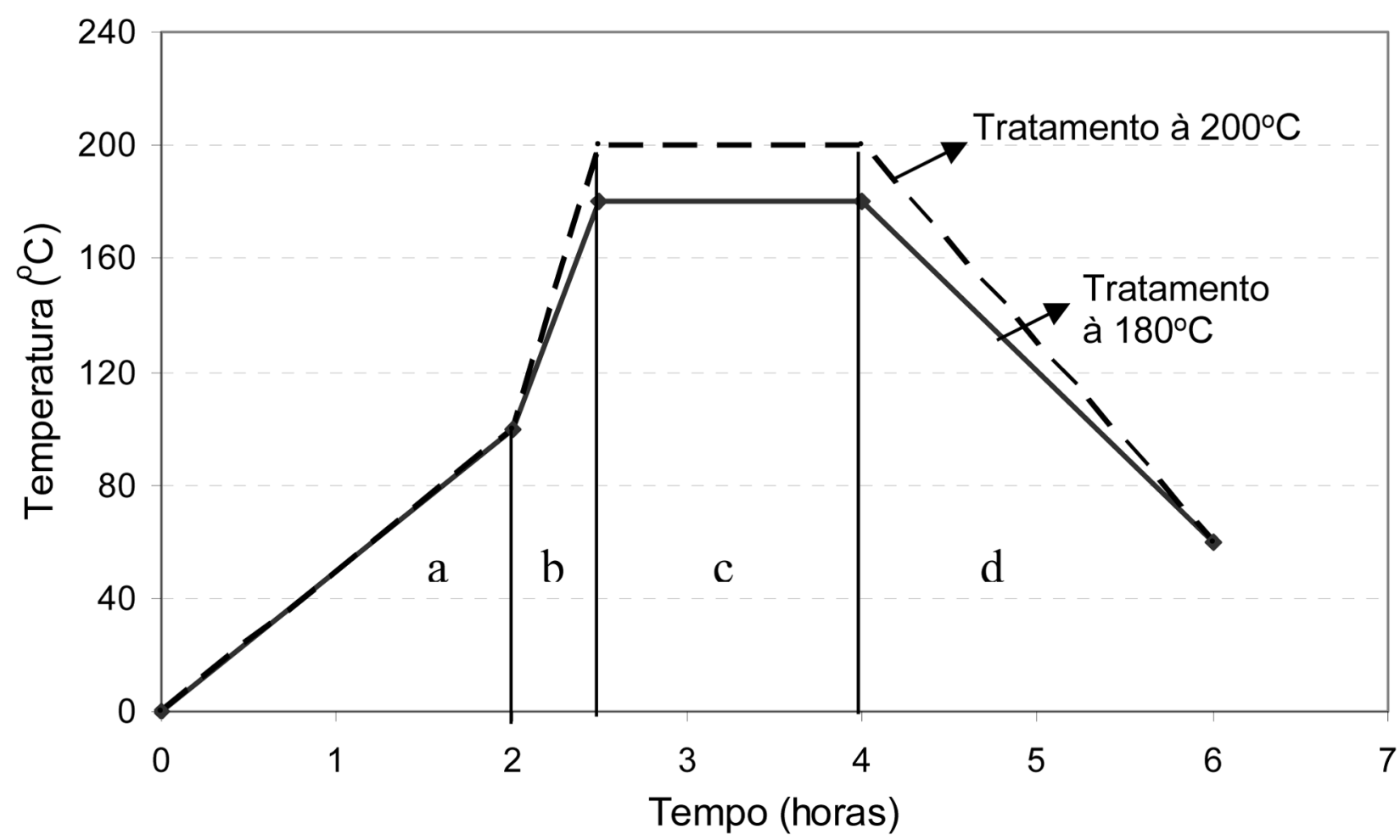

Figura 1. Programa de temperatura vs. tempo dos tratamentos térmicos aplicados às madeiras de Corymbia citriodora e Eucalyptus pellita. a: aquecimento até $100^{\circ} \mathrm{C}$. b: aumento da temperatura de $100^{\circ} \mathrm{C}$ até a temperatura final $\left(180\right.$ ou $\left.200^{\circ} \mathrm{C}\right)$. c: tempo de tratamento na temperatura final. d: resfriamento.

Figure 1. Program of temperature vs. time for heat treatments applied to Corymbia citriodora and Eucalyptus pellita woods. a: heating up to $100^{\circ} \mathrm{C}$. b: temperature increasing from $100^{\circ} \mathrm{C}$ to final temperature ( 180 or $200^{\circ} \mathrm{C}$ ). c: treatment time in the final temperature. $\mathrm{d}$ : cooling.

\section{Colagem das juntas de madeira}

Antes da colagem das juntas de madeira, realizou-se uma classificação visual das amostras, sendo selecionadas aquelas livres de defeitos tais como rachaduras, empenamentos e superfícies contaminadas por extrativos (bolsões de goma). Em seguida, as amostras foram desempenadas e aplainadas, obtendo-se dimensões finais de 315 x 54 x 19 mm (comprimento x largura x espessura).

Para a colagem das juntas de madeira não tratadas (controle) e tratadas a 180 e $200^{\circ} \mathrm{C}$ de ambas as espécies, foram utilizados três adesivos: resorcinol à 100\%, resorcinol-tanino 80:20 e resorcinol-tanino 60:40. O resorcinol e o tanino de acácia negra (Acacia mearnsii De Wild) foram obtidos na TANAC S.A. O tanino foi obtido em forma de pó, sendo preparada uma solução na proporção de 1:1 (adesivo: água) com o auxílio do processador Mondial Multi Mixer Premiun. Para todos os adesivos, adicionou-se o catalisador paraformaldeído na proporção de 1:5 (catalisador: adesivo), o qual foi misturado por aproximadamente 5 minutos. As propriedades físicas e químicas dos adesivos são apresentadas na Tabela 1 . O adesivo foi aplicado às juntas de madeira, à temperatura ambiente de $22^{\circ} \mathrm{C}$, com o auxílio de um rolo de espuma, sendo utilizados $11,2 \mathrm{~g}$ de adesivo por junta, ou seja, 330 g.m² de gramatura. O número de juntas coladas foi igual à dois.

Tabela 1. Propriedades físicas e químicas dos adesivos.

Table 1. Physical and chemical properties of the adhesives.

\begin{tabular}{lccccc}
\hline Adesivo & Densidade $\left(\mathbf{g} \cdot \mathbf{c m}^{-3}\right)$ & Teor de sólidos (\%) & Viscosidade (cp) & pH & Temperatura $\left({ }^{\circ} \mathbf{C}\right)$ \\
\hline Resorcinol & 0,99 & 71,76 & 474,57 & 8,23 & 26,2 \\
Resorcinol-tanino 80:20 & 1,07 & 64,06 & 541,76 & 8,24 & 29,0 \\
Resorcinol-tanino 60:40 & 1,08 & 58,50 & 418,75 & 7,98 & 30,0 \\
\hline
\end{tabular}


A prensagem das juntas foi realizada através de uma adaptação feita à máquina universal de ensaios mecânicos da CONTENCO, com capacidade de 30 toneladas. Para tal, foram utilizadas três peças de madeira livre de defeitos cujas dimensões foram de 450 x 200 x 65 mm (comprimento x largura x espessura) (Figura 2). As peças de madeira foram ligadas através de quatro eixos rosqueados dispostos nas extremidades. A carga aplicada foi de $10 \mathrm{kgf.cm}{ }^{-2}$. As juntas foram armazenadas em um ambiente a $24^{\circ} \mathrm{C}$ por um período de 8 horas e posteriormente acondicionadas em câmara climática a $20^{\circ} \mathrm{C}$ e $65 \%$ de UR por uma semana.
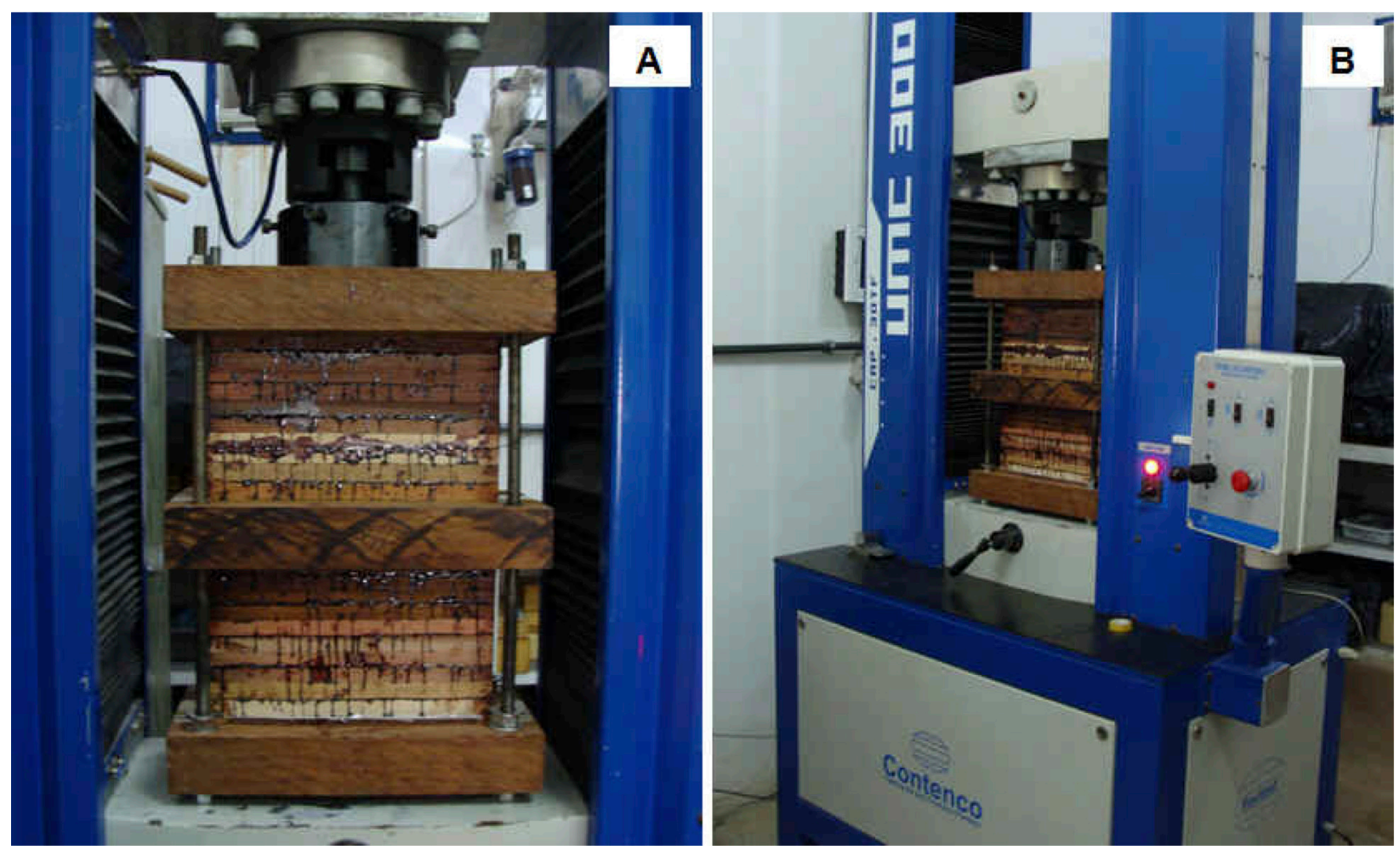

Figura 2. Prensagem das juntas coladas das madeiras de Corymbia citriodora e Eucalyptus pellita tratadas e não tratadas termicamente.

Figure 2. Pressing of the glued joints of the untreated and heat treated Corymbia citriodora and Eucalyptus pellita woods.

No total foram colados 36 pares de juntas de madeira, sendo 18 pares por espécie. Para a prensagem, foram dispostas da seguinte forma: entre a primeira e a segunda peça de madeira foram colocados 5 pares de juntas e entre a segunda e terceira outros 5 pares. Esse procedimento foi repetido por três vezes. Entretanto, na última prensagem foram colados 6 pares de juntas. A Tabela 2 apresenta o delineamento experimental utilizado para a colagem das juntas de madeira.

\section{Ensaio de resistência ao cisalhamento}

A qualidade de adesão das madeiras não tratadas e tratadas a 180 e $200^{\circ} \mathrm{C}$ foi avaliada através da resistência ao cisalhamento na compressão paralela às fibras $\left(f_{v}\right)$ na linha de cola e na madeira sólida. O ensaio de cisalhamento foi realizado na máquima universal de ensaios da CONTENCO à temperatura ambiente $\left(20^{\circ} \mathrm{C}\right)$.

As amostras de madeira colada foram preparadas de acordo com as dimensões estipuladas pela norma ASTM D 905-94 (Figura 3A). As juntas de madeira colada também foram comparadas com a madeira sólida não tratada e tratadas a 180 e $200^{\circ} \mathrm{C}$, para ambas as espécies. As dimensões das amostras de madeira sólida foram definidas segundo a norma ASTM D 143-94 (Figura 3B). No total, foram realizadas 10 repetições para cada combinação de tratamento. 
Tabela 2. Delineamento experimental utilizado para a colagem das juntas de madeira de Corymbia citriodora e Eucalyptus pellita.

Table 2. Experimental design used for the glued joints of the Corymbia citriodora and Eucalyptus pellita woods.

\begin{tabular}{|c|c|c|}
\hline Espécie & Temperatura & Adesivo \\
\hline \multirow{9}{*}{ Corymbia citriodora } & \multirow{3}{*}{ Ambiente (controle) } & Resorcinol \\
\hline & & Resorcinol-tanino 80:20 \\
\hline & & Resorcinol-tanino 60:40 \\
\hline & \multirow{3}{*}{$180^{\circ} \mathrm{C}$} & Resorcinol \\
\hline & & Resorcinol-tanino 80:20 \\
\hline & & Resorcinol-tanino 60:40 \\
\hline & \multirow{3}{*}{$200^{\circ} \mathrm{C}$} & Resorcinol \\
\hline & & Resorcinol-tanino 80:20 \\
\hline & & Resorcinol-tanino 60:40 \\
\hline \multirow{9}{*}{ Eucalyptus pellita } & \multirow{3}{*}{ Ambiente (controle) } & Resorcinol \\
\hline & & Resorcinol-tanino 80:20 \\
\hline & & Resorcinol-tanino 60:40 \\
\hline & \multirow{3}{*}{$180^{\circ} \mathrm{C}$} & Resorcinol \\
\hline & & Resorcinol-tanino 80:20 \\
\hline & & Resorcinol-tanino 60:40 \\
\hline & \multirow{3}{*}{$200^{\circ} \mathrm{C}$} & Resorcinol \\
\hline & & Resorcinol-tanino $80: 20$ \\
\hline & & Resorcinol-tanino 60:40 \\
\hline
\end{tabular}

A

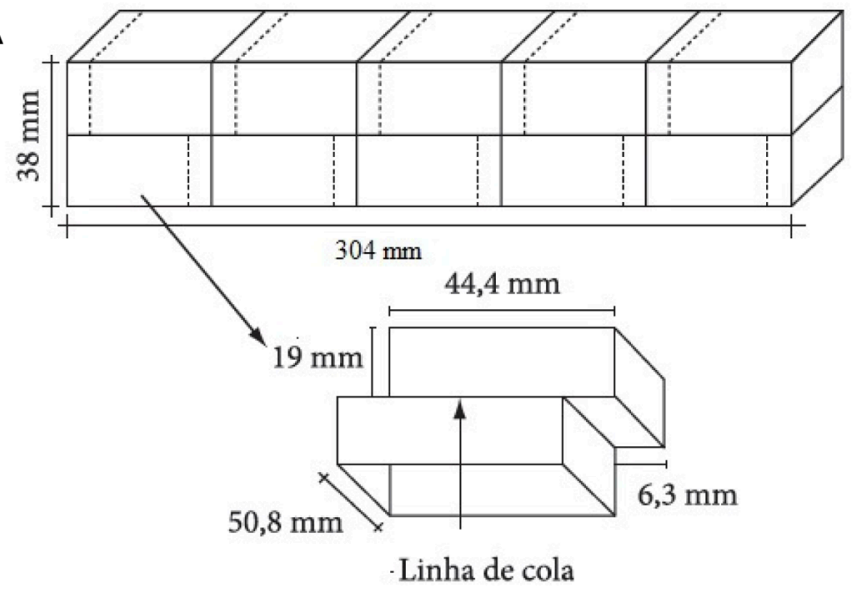

B

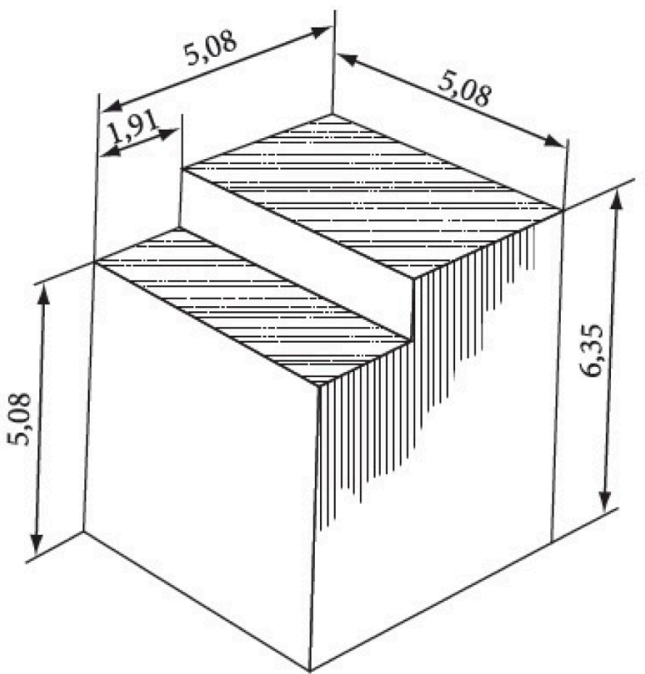

Figura 3. Dimensões dos corpos de prova para o teste de cisalhamento à compressão paralela às fibras das juntas coladas (A) e da madeira sólida (B) segundo as normas ASTM D 905-94 e ASTM D 143-94, respectivamente.

Figure 3. Dimension of samples for shear strength parallel to the grain testing to glued joints $(A)$ and solid wood (B) according to ASTM D 905-94 and ASTM D 143-94 standards, respectively.

O ângulo de orientação dos anéis de crescimento em relação à superfície de colagem foi determinado para cada junta com o auxílio de um transferidor, já que esta característica pode afetar a penetração do adesivo na madeira. O ângulo de $90^{\circ}$ caracteriza a superfície radial da madeira, o ângulo de $0^{\circ}$ a superfície tangencial enquanto que os ângulos $>90^{\circ}$ e entre $0^{\circ}$ e $90^{\circ}$ caracterizam as superfícies diagonais.

Após os ensaios de cisalhamento, as amostras foram separadas em dois grupos, sendo o primeiro destinado à determinação da densidade aparente e do teor de umidade e o segundo destinado à determinação da porcentagem de falhas na madeira.

\section{Determinação da densidade e do teor de umidade das juntas coladas de madeira}

A densidade aparente e o teor de umidade das juntas não tratadas e tratadas termicamente foram determinados segundo a norma ASTM D 2395-99. Para o cálculo da densidade aparente foi utilizado o método de imersão em mercúrio (método D), sendo esta calculada através das seguintes equações: 


$$
\begin{aligned}
& \operatorname{DENS}_{\hat{f} V}=M / V \\
& V=P / 13,5409
\end{aligned}
$$

onde, $\mathrm{DENS}_{\mathrm{fv}}$ : densidade aparente das juntas de madeira no teor de umidade de equilíbrio $\left(\mathrm{g} \cdot \mathrm{cm}^{-3}\right)$; M: massa no teor de umidade de equilíbrio (g); V: volume da amostra de madeira obtido através do método de imersão do mercúrio $\left(\mathrm{cm}^{3}\right)$; e P: peso da amostra de madeira imersa em mercúrio $(\mathrm{g})$. $\mathrm{O}$ valor de 13,5409 corresponde à densidade do mercúrio a $22^{\circ} \mathrm{C}\left(\mathrm{g} \cdot \mathrm{cm}^{-3}\right)$.

O teor de umidade das juntas foi calculado através da seguinte equação:

$$
T U E_{f v}=\left(P_{U}-P_{S}\right) / P_{S} \times 100
$$

onde, $\mathrm{TUE}_{\mathrm{fv}}$ : teor de umidade (\%); $\mathrm{P}_{\mathrm{U}}$ : peso da amostra obtido após acondicionamento em câmara climática a $20^{\circ} \mathrm{C}$ e $65 \%$ UR (g); e $\mathrm{P}_{\mathrm{s}}$ : peso seco da amostra obtido após secagem em estufa a $103 \pm$ $2^{\circ} \mathrm{C}(\mathrm{g})$.

\section{Determinação da porcentagem de falhas na madeira}

A porcentagem de falhas na madeira foi avaliada segundo a norma ASTM D 3110-94, a qual requer um valor médio superior a $60 \%$ de falha na madeira e um mínimo de $90 \%$ de amostras com um mínimo de 30\% de falha na madeira, na qual nenhuma junta deve apresentar $0 \%$ de falha.

A análise foi realizada com o auxílio de uma rede de quadrícula, em escala milimétrica, através da quantificação das áreas em que houve adesão, ou seja, com presença de madeira. O método empregado pode ser observado na Figura 4.
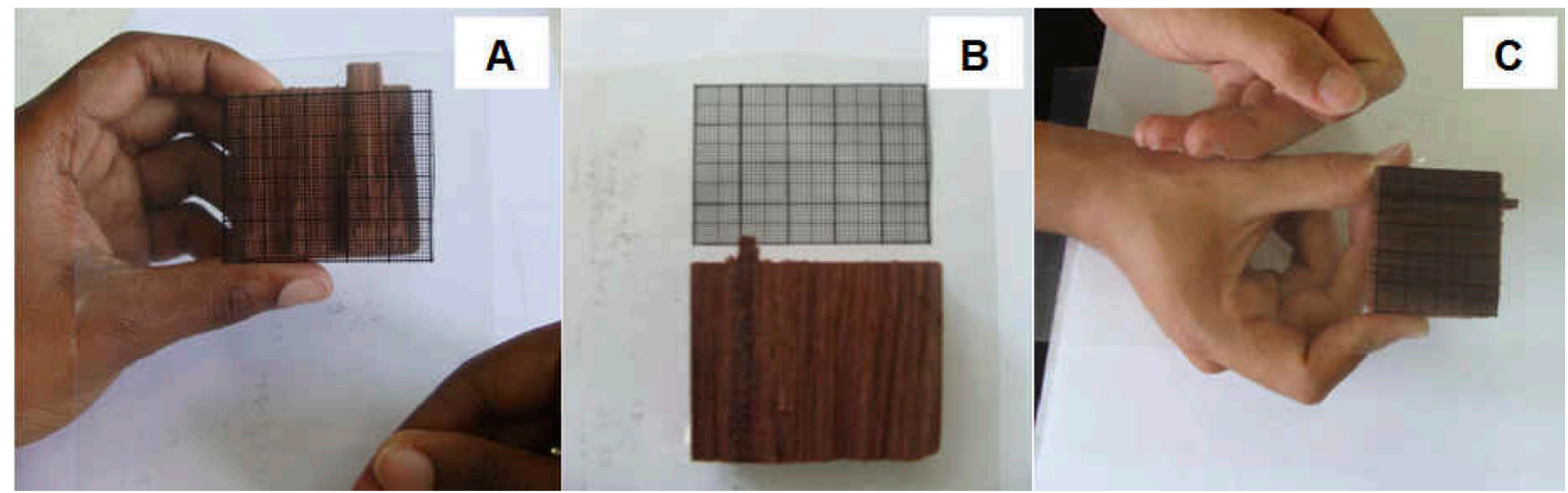

Figura 4. Método utilizado para determinar a porcentagem de falhas nas madeiras de Corymbia citriodora e Eucalyptus pellita.

Figure 4. Method used to determine the wood failure percentage on the Corymbia citriodora and Eucalyptus pellita woods.

\section{Determinação da porosidade da madeira}

A porosidade da madeira foi calculada através da fórmula proposta por MacLean (1952), a qual estabelece que a porosidade é função da densidade e do teor de umidade da madeira:

$$
V a=1-\operatorname{DENS}_{\hat{f}}\left(0,667+0,01 T U_{f i}\right) \times 100
$$

onde, Va: porcentagem de vazios ou porosidade da madeira (\%); DENS $_{\mathrm{fv}}$ : densidade aparente da madeira $\left(\mathrm{g} \mathrm{cm}^{-3}\right)$; e $\mathrm{TU}_{\mathrm{fv}}$ : teor de umidade da madeira.

\section{Determinação do pH da madeira}

$\mathrm{O}$ pH das madeiras não tratadas e tratadas termicamente foi determinado de acordo com a metodologia proposta por Lelis (1995). O material foi fragmentado em palitos de madeira, moído em um moinho de facas SL31 SOLAB e seco em estufa a $103 \pm 2{ }^{\circ} \mathrm{C}$ durante 24 horas. A partir do material seco, 5 gramas de madeira foram pesadas e imersas em água destilada por 24 horas. Em seguida, o material foi filtrado, obtendo-se uma solução na qual determinou-se o pH. Foram realizadas 3 repetições para cada amostra de cada tratamento. 


\section{Análises estatísticas}

As análises estatíticas foram realizadas com o auxílio do programa STATISTICA 7.0, sendo todos os testes analisados à $95 \%$ de probabilidade. A normalidade dos dados foi verificada através do teste de Kolmogorov-Smirnov e a homogeneidade das variâncias através do teste de Levene.

A resistência ao cisalhamento $\left(\mathrm{f}_{\mathrm{v}}\right)$ das juntas coladas e da madeira sólida apresentaram uma distribuição normal dos dados, portanto, realizou-se uma análise de variância (ANOVA) e aplicou-se o teste de Tukey para verificar as diferenças significativas entre as médias dos tratamentos.

Para comparar o efeito da densidade e do teor de umidade entre a madeira sólida e as juntas coladas, realizou-se uma ANOVA quando os dados apresentaram distribuição normal e o teste de Wilcoxon-Mann-Whitney, quando encontrada não-normalidade dos dados.

Para o pH da madeira ( $\left.\mathrm{pH}_{\text {madeira }}\right)$, aplicou-se o teste não-paramétrico de Kruskal-Wallis para comparação entre as médias, já que os dados não apresentaram distribuição normal, mesmo após a transformação dos dados.

Para os dados de densidade e teor de umidade das juntas coladas e da madeira sólida $\left(\mathrm{DENS}_{\mathrm{fv}} \mathrm{e}\right.$ $\mathrm{TUE}_{\mathrm{fv}}$ respectivamente), de porcentagem de falhas na madeira, de ângulo de orientação dos anéis de crescimento em relação à superfície de colagem, porosidade e $\mathrm{pH}$ da madeira foram realizadas análises de correlação a fim de verificar o efeito de cada uma dessas variáveis na resistência ao cisalhamento.

Para avaliar a qualidade de adesão das madeiras tratadas termicamente foram consideradas as seguintes variáveis independentes: espécie de madeira (Corymbia citriodora e Eucalyptus pellita), temperatura (ambiente ou controle, 180 e $200^{\circ} \mathrm{C}$ ) e adesivo (resorcinol, resorcinol-tanino 80:20 e resorcinol-tanino 60:40), enquanto que as variáveis dependentes foram: $f_{v^{\prime}} \operatorname{DENS}_{\mathrm{fv}^{\prime}} \operatorname{TUE}_{\mathrm{fv}^{\prime}}$ falha, ângulo, porosidade e $\mathrm{pH}_{\text {madeira }}$.

\section{RESULTADOS E DISCUSSÃO}

\section{pH da madeira}

A Tabela 3 apresenta os valores médios do $\mathrm{pH}$ das madeiras não tratadas e tratadas termicamente de ambas as espécies.

Tabela 3. Médias do $\mathrm{pH}$ das madeiras de Corymbia citriodora e Eucalyptus pellita não tratadas e tratadas termicamente.

Table 3. Means of the $\mathrm{pH}$ of the untreated and heat treated Corymbia citriodora and Eucalyptus pellita woods.

\begin{tabular}{lcc}
\hline \multirow{2}{*}{ Temperatura $\left({ }^{\circ} \mathrm{C}\right)$} & \multicolumn{2}{c}{ pH da madeira } \\
\cline { 2 - 3 } & Corymbia citriodora & Eucalyptus pellita \\
\hline Controle & $6,32[30,50] \mathrm{a}$ & $4,90[30,50] \mathrm{a}$ \\
180 & $4,10[9,62] \mathrm{b}$ & $4,09[12,95] \mathrm{b}$ \\
200 & $4,23[15,37] \mathrm{b}$ & $4,08[12,04] \mathrm{b}$ \\
\hline
\end{tabular}

Valores entre colchetes $=$ média dos postos feitos pelo teste de Kruskal-Wallis. Médias com a mesma letra não são estatisticamente iguais entre si.

Os valores de $\mathrm{pH}$ das madeiras de Corymbia citriodora e Eucalyptus pellita não tratadas $(6,32$ e 4,90, respectivamente) estão próximos daqueles mencionados por outros autores. Boonstra et al. (2007) afirmam que as madeiras não tratadas geralmente apresentam um pH próximo à 5,0-5,5. Entretanto, observa-se que o tratamento térmico afetou significativamente o $\mathrm{pH}$ da madeira de ambas as espécies, tornando-as mais ácidas, independentemente da temperatura utilizada. Este efeito foi mais evidente para Corymbia citriodora, cujo $\mathrm{pH}$ foi reduzido de 6,32 na madeira não tratada para 4,10 e 4,23 nas madeiras tratadas a 180 e $200^{\circ} \mathrm{C}$, respectivamente. Estes resultados corroboram com a afirmação de Boonstra et al. (2007) de que o tratamento térmico reduz o pH da madeira à 3,5-4,0 devido à produção de ácidos acético e fórmico durante o tratamento.

Mirzaei et al. (2012) também observaram uma redução no pH da madeira de Fagus orientalis (folhosa) tratada a 130 e $150^{\circ} \mathrm{C}$ durante 30 minutos. A madeira não tratada apresentou um pH de 5,4 e após os tratamentos, o pH foi reduzido à 4,83 e 4,52, respectivamente. Resultados similares foram encontrados por Kol et al. (2009). Esses autores verificaram que, após o tratamento a $180^{\circ} \mathrm{C}$ durante 2 horas, o pH das madeiras de Erythrophleum ivorense e Chlorophora excelsa foi reduzido de 4,04 para 3,90 e de 6,42 para 5,45, respectivamente. 


\section{Resistência ao cisalhamento}

A Tabela 4 apresenta os valores médios de resistência ao cisalhamento da madeira sólida e das juntas coladas.

O tratamento térmico afetou negativamente a resistência ao cisalhamento da madeira sólida e das juntas coladas de ambas as espécies. A madeira sólida de Corymbia citriodora apresentou uma redução superior à 70\% na resistência ao cisalhamento para ambas as temperaturas quando comparada à madeira sólida não tratada, enquanto que para a madeira sólida de Eucalyptus pellita foram encontradas reduções entre 53 e $63 \%$ para as temperaturas de 180 e $200^{\circ} \mathrm{C}$, respectivamente (Figura 5). Estes resultados são superiores aqueles citados pela FTA (2003), o qual cita que a resistência ao cisalhamento da madeira tratada termicamente pode apresentar reduções de até $25 \%$ na direção radial e $40 \%$ na direção tangencial para madeiras tratadas à altas temperaturas $\left(230^{\circ} \mathrm{C}\right.$ por 4 horas) e de até $20 \%$ nas direções radial e tangencial para madeiras tratadas à temperaturas mais baixas $\left(190^{\circ} \mathrm{C}\right)$.

Tabela 4. Médias da resistência ao cisalhamento das juntas coladas e das madeiras sólidas, da densidade e do teor de umidade de equilíbrio das madeiras de Corymbia citriodora e Eucalyptus pellita não tratadas e tratadas termicamente.

Table 4. Means of the shear strength of the glued joints and solid wood, density and moisture content of the untreated and heat-treated Corymbia citriodora and Eucalyptus pellita woods.

\begin{tabular}{|c|c|c|c|c|c|c|c|c|}
\hline \multirow{2}{*}{ Material } & \multirow{2}{*}{ Temperatura $\left({ }^{\circ} \mathrm{C}\right)$} & \multirow{2}{*}{ Adesivo } & \multicolumn{2}{|c|}{$\mathrm{f}_{v}(\mathrm{MPa})$} & \multicolumn{2}{|c|}{$\operatorname{DENS}_{\mathrm{fv}}\left(\mathrm{g} . \mathrm{cm}^{-3}\right)$} & \multicolumn{2}{|c|}{$\mathrm{TU}_{\mathrm{fv}}(\%)$} \\
\hline & & & Cc & Ep & Cc & Ep & Cc & Ep \\
\hline \multirow{9}{*}{ Juntas coladas } & \multirow{3}{*}{ Controle } & $\mathrm{R}$ & $\begin{array}{c}11,02 \mathrm{~b} \\
(0,99)\end{array}$ & $\begin{array}{c}12,22 \mathrm{ab} \\
(1,00)\end{array}$ & $\begin{array}{c}0,809 \\
(0,038)\end{array}$ & $\begin{array}{c}0,727 \\
(0,020)\end{array}$ & $\begin{array}{l}11,50 \\
(0,43) \\
\end{array}$ & $\begin{array}{l}11,73 \\
(0,72)\end{array}$ \\
\hline & & RT 80:20 & $\begin{array}{c}12,40 \mathrm{a} \\
(1,23)\end{array}$ & $\begin{array}{c}12,85 \mathrm{ab} \\
(1,60)\end{array}$ & $\begin{array}{c}0,853 \\
(0,032)\end{array}$ & $\begin{array}{c}0,722 \\
(0,037)\end{array}$ & $\begin{array}{l}11,74 \\
(0,24) \\
\end{array}$ & $\begin{array}{l}11,79 \\
(0,21)\end{array}$ \\
\hline & & RT 60:40 & $\begin{array}{c}6,74 \mathrm{~cd} \\
(1,33)\end{array}$ & $\begin{array}{c}10,84 \mathrm{~b} \\
(1,10)\end{array}$ & $\begin{array}{c}0,854 \\
(0,018)\end{array}$ & $\begin{array}{c}0,719 \\
(0,047)\end{array}$ & $\begin{array}{c}12,82 \\
(1,29)\end{array}$ & $\begin{array}{l}12,27 \\
(0,21)\end{array}$ \\
\hline & \multirow{3}{*}{180} & $\mathrm{R}$ & $\begin{array}{c}6,16 \text { cde } \\
(1,33)\end{array}$ & $\begin{array}{c}6,47 \mathrm{~cd} \\
(1,50)\end{array}$ & $\begin{array}{c}0,753 \\
(0,074)\end{array}$ & $\begin{array}{c}0,681 \\
(0,061)\end{array}$ & $\begin{array}{c}4,11 \\
(0,76)\end{array}$ & $\begin{array}{c}3,78 \\
(0,96)\end{array}$ \\
\hline & & RT 80:20 & $\begin{array}{l}7,54 \mathrm{c} \\
(1,21)\end{array}$ & $\begin{array}{l}7,02 \mathrm{c} \\
(1,05)\end{array}$ & $\begin{array}{c}0,737 \\
(0,082)\end{array}$ & $\begin{array}{c}0,694 \\
(0,033)\end{array}$ & $\begin{array}{c}4,73 \\
(1,75)\end{array}$ & $\begin{array}{c}3,81 \\
(0,46)\end{array}$ \\
\hline & & RT 60:40 & $\begin{array}{c}6,61 \mathrm{~cd} \\
(1,32)\end{array}$ & $\begin{array}{c}4,52 \text { defg } \\
(1,56)\end{array}$ & $\begin{array}{c}0,709 \\
(0,060)\end{array}$ & $\begin{array}{c}0,651 \\
(0,027)\end{array}$ & $\begin{array}{c}4,97 \\
(1,01)\end{array}$ & $\begin{array}{c}3,80 \\
(1,01)\end{array}$ \\
\hline & \multirow{3}{*}{200} & $\mathrm{R}$ & $\begin{array}{c}5,58 \text { cde } \\
(1,36)\end{array}$ & $\begin{array}{c}5,53 \text { cdef } \\
(1,41)\end{array}$ & $\begin{array}{c}0,701 \\
(0,029)\end{array}$ & $\begin{array}{c}0,681 \\
(0,025)\end{array}$ & $\begin{array}{c}3,31 \\
(0,54)\end{array}$ & $\begin{array}{c}3,25 \\
(1,59)\end{array}$ \\
\hline & & RT 80:20 & $\begin{array}{c}4,07 \text { efg } \\
(1,13)\end{array}$ & $\begin{array}{c}5,14 \text { cdefg } \\
(0,85)\end{array}$ & $\begin{array}{c}0,673 \\
(0,013)\end{array}$ & $\begin{array}{c}0,681 \\
(0,016)\end{array}$ & $\begin{array}{c}3,57 \\
(0,79)\end{array}$ & $\begin{array}{c}3,23 \\
(0,58)\end{array}$ \\
\hline & & RT 60:40 & $\begin{array}{c}5,84 \text { cde } \\
(1,48)\end{array}$ & $\begin{array}{c}6,12 \text { cde } \\
(1,35)\end{array}$ & $\begin{array}{c}0,705 \\
(0,028)\end{array}$ & $\begin{array}{c}0,674 \\
(0,020)\end{array}$ & $\begin{array}{c}3,43 \\
(0,88)\end{array}$ & $\begin{array}{c}2,78 \\
(0,99)\end{array}$ \\
\hline \multirow{3}{*}{ Madeira sólida } & \multicolumn{2}{|l|}{ Controle } & $\begin{array}{c}14,06 \mathrm{a} \\
(2,02)\end{array}$ & $\begin{array}{c}14,06 \mathrm{a} \\
(2,02)\end{array}$ & $\begin{array}{c}0,809 \\
(0,049)\end{array}$ & $\begin{array}{c}0,706 \\
(0,068)\end{array}$ & $\begin{array}{l}12,16 \\
(0,22)\end{array}$ & $\begin{array}{l}11,49 \\
(0,15)\end{array}$ \\
\hline & \multicolumn{2}{|l|}{180} & $\begin{array}{c}3,29 \mathrm{fg} \\
(1,43)\end{array}$ & $\begin{array}{c}6,54 \mathrm{~cd} \\
(1,52)\end{array}$ & $\begin{array}{c}0,708 \\
(0,013)\end{array}$ & $\begin{array}{c}0,684 \\
(0,019)\end{array}$ & $\begin{array}{c}4,51 \\
(0,32)\end{array}$ & $\begin{array}{c}4,09 \\
(0,46)\end{array}$ \\
\hline & \multicolumn{2}{|l|}{200} & $\begin{array}{l}3,05 \mathrm{~g} \\
(0,64)\end{array}$ & $\begin{array}{c}5,17 \text { cdefg } \\
(1,04)\end{array}$ & $\begin{array}{c}0,698 \\
(0,048)\end{array}$ & $\begin{array}{c}0,662 \\
(0,030)\end{array}$ & $\begin{array}{c}3,74 \\
(0,36)\end{array}$ & $\begin{array}{c}3,48 \\
(0,57)\end{array}$ \\
\hline
\end{tabular}

R: resorcinol. RT: resorcinol-tanino. Cc: Corymbia citriodora. Ep: Eucalyptus pellita. $\mathrm{f}$ : resistência ao cisalhamento na compressão paralela às fibras. DENS $_{\mathrm{fv}}$ : densidade das juntas de madeira. $\mathrm{TU}_{\mathrm{fv}}$ : teor de umidade das juntas. Valores entre parênteses = desvio padrão. Médias com a mesma letra não são estatisticamente diferentes entre si.

Ghalehno e Nazerian (2011) também observaram reduções entre 20,8 e 22,7\% na resistência ao cisalhamento da madeira sólida de Carpinus betulus (folhosa) tratada a $190^{\circ} \mathrm{C}$ durante 6 e 9 horas, respectivamente. A espécie Carpinus betulus estudada por esses autores apresentou uma densidade aparente a $12 \%$ de umidade de $0,710 \mathrm{~g} \cdot \mathrm{cm}^{-3}$, a qual está próxima à densidade das madeiras de Corymbia citriodora e Eucalyptus pellita avaliadas neste estudo. Portanto, as maiores reduções na resistência ao cisalhamento das madeiras sólidas observadas neste estudo para as espécies de Corymbia citriodora e Eucalyptus pellita não depende da densidade da madeira mas provavelmente de outros fatores inerentes à espécie (ex.: composição química), mostrando que ambas são mais susceptíveis à degradação térmica que as espécies estudadas por outros autores. 

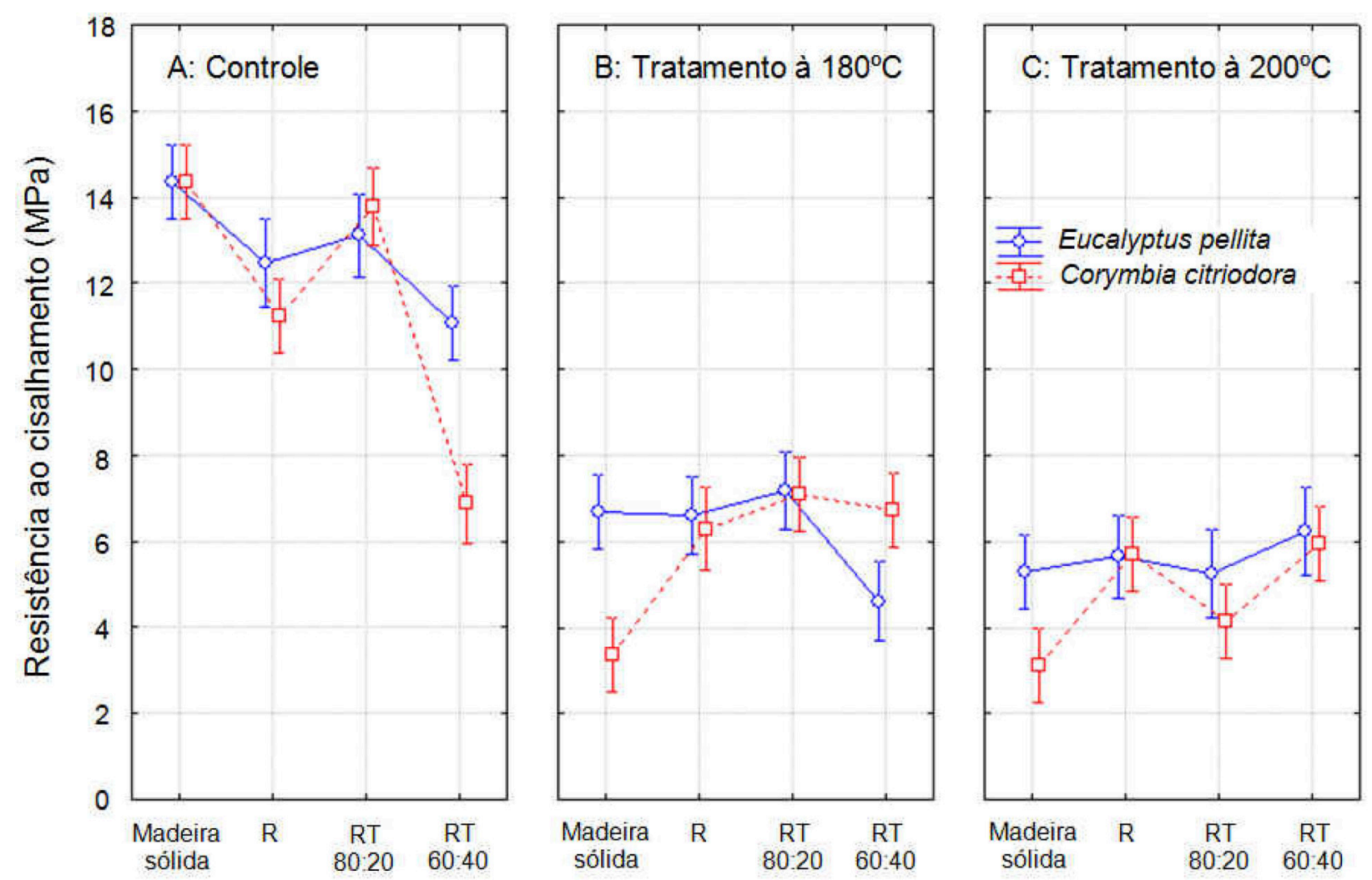

Figura 5. Resistência ao cisalhamento na compressão paralela às fibras das juntas coladas e da madeira sólida de Corymbia citriodora e Eucalyptus pellita não tratadas e tratadas termicamente. R: resorcinol. RT: resorcinol-tanino.

Figure 5. Shear strength parallel to the grain of the untreated and heat treated glued joints and solid wood of the Corymbia citriodora and Eucalyptus pellita. R: resorcinol. RT: resorcinol-tannin.

As análises estatísticas mostraram uma tripla interação entre espécie, adesivo e temperatura para a resistência ao cisalhamento (Tabela 5). A resistência ao cisalhamento das madeiras sólidas não tratadas das espécies estudadas não apresentam diferenças significativas entre si. Entretanto, após os tratamentos térmicos, os valores de resistência ao cisalhamento apresentam diferenças entre as epécies.

Tabela 5. Valores de $\mathrm{F}$ obtidos pela análise de variância (ANOVA) para a resistência ao cisalhamento das juntas coladas das madeiras de Corymbia citriodora e Eucalyptus pellita.

Table 5. F values obtained by the analysis of variance (ANOVA) to shear strength of the glued joints of the Corymbia citriodora and Eucalyptus pellita woods.

\begin{tabular}{lcc}
\hline Fonte de variação & Valor de $\boldsymbol{F}$ & $\boldsymbol{P}$ \\
\hline Espécie & $19,02^{*}$ & 0,00002 \\
Adesivo & $11,24^{*}$ & 0,00000 \\
Temperatura & $542,27^{*}$ & 0,0000 \\
Espécie*adesivo & $3,85^{*}$ & 0,01048 \\
Espécie*temperatura & $1,51^{\mathrm{NS}}$ & 0,22346 \\
Adesivo*temperatura & $28,97^{*}$ & 0,0000 \\
Espécie*adesivo*temperatura & $11,27^{*}$ & 0,00000 \\
\hline
\end{tabular}

* Significativo à $95 \%$ de probabilidade. ${ }^{\text {Ns }}$ Não significativo.

As juntas de madeira não tratada coladas com o adesivo RT 80:20, de ambas as espécies apresentaram valores de resistência ao cisalhamento mais próximos daqueles obtidos para a madeira sólida não tratada (14,06 MPa). Os valores de resistência ao cisalhamento das juntas de madeira de Corymbia citriodora e Eucalyptus pellita não tratadas foram de 12,40 e 12,85 $\mathrm{MPa}$, respectivamente, os quais não apresentaram diferenças significativas entre si (Figura 5A).

A resistência ao cisalhamento das juntas de madeira de Corymbia citriodora não tratada apresentou diferenças significativas entre os adesivos. Neste caso, a resistência das juntas coladas com o 
adesivo RT 80:20 apresentou o melhor desempenho (12,40 MPa) com um valor médio estatisticamente igual ao da madeira sólida (14,06 MPa) (Tabela 4). Por outro lado, o adesivo RT 60:40 apresentou o pior desempenho (6,74 MPa), o qual pode ser explicado pelo seu menor teor de sólidos $(58,5 \%)$ quando comparado aos demais adesivos utilizados (Tabela 2$)$.

Para as juntas de madeira de Eucalyptus pellita não tratada, os valores de resistência ao cisalhamento foram de 12,22 MPa para o adesivo resorcinol, 12,85 MPa para o adesivo RT 80:20 e 10,84 MPa para o adesivo RT 60:40, os quais não apresentaram diferenças significativas entre si (Tabela 4). Entretanto, quando comparados ao valor de resistência ao cisalhamento da madeira sólida, o adesivo RT 60:40 apresentou uma resistência estatisticamente inferior.

As madeiras sólidas e as juntas coladas não tratadas de ambas as espécies não apresentaram diferenças significativas entre si para a densidade e o teor de umidade (Tabela 6). Isso mostra que tanto a densidade quanto o teor de umidade não influenciaram os resultados obtidos para a resistência ao cisalhamento, quando compara-se as juntas à madeira sólida. Segundo Rowell (2005), as alterações no teor de umidade da madeira abaixo do ponto de saturação das fibras apresentam um impacto nas propriedades mecânicas da madeira, enquanto que a resistência mecânica é proporcional à densidade.

Tabela 6. Valores de F obtidos pela análise de variância (ANOVA) e valores de $Z$ obtidos pelo teste de Wilcoxon-Mann-Whitney para a comparação das médias das propriedades físicas entre a madeira sólida e as juntas de cada tratamento.

Table 6. F values obtained by the analysis of variance (ANOVA) and $Z$ values obtained by the Wilcoxon-Mann-Whitney test to compare means of the physical properties between solid wood and glued joints for each treatment.

\begin{tabular}{|c|c|c|c|c|}
\hline \multirow{2}{*}{ Tratamento } & \multicolumn{2}{|c|}{ DENS $_{f v}$} & \multicolumn{2}{|c|}{$\mathbf{T U}_{\mathrm{fv}}$} \\
\hline & Corymbia citriodora & Eucalyptus pellita & Corymbia citriodora & Eucalyptus pellita \\
\hline Controle & $4,05^{\mathrm{NS}}$ & $(-0,98)^{N S}$ & $0,21^{\mathrm{NS}}$ & $1,24^{\mathrm{NS}}$ \\
\hline $180^{\circ} \mathrm{C}$ & $1,84^{\mathrm{NS}}$ & $(-0,79)^{\mathrm{NS}}$ & $(3,61)^{*}$ & $(-1,47)^{\mathrm{NS}}$ \\
\hline $200^{\circ} \mathrm{C}$ & $(-0,12)^{\mathrm{NS}}$ & $0,36^{\mathrm{NS}}$ & $(-0,28)^{N S}$ & $(-1,02)^{\mathrm{NS}}$ \\
\hline
\end{tabular}

Valores entre parênteses $=$ valores de Z. * Significativo à $95 \%$ de probabilidade. ${ }^{\text {Ns }}$ Não significativo.

As juntas de madeira de Corymbia citriodora tratada a $180^{\circ} \mathrm{C}$ apresentaram valores de resistência ao cisalhamento estatisticamente iguais para os três adesivos, sendo de 6,16, 7,54 e 6,61 MPa para os adesivos resorcinol, RT 80:20 e RT 60:40, respectivamente. Esses valores foram próximos daqueles obtidos para as juntas de madeira não tratada coladas com o adesivo RT 60:40 (6,74 MPa). Entretanto, esses valores foram superiores ao encontrado para a madeira sólida tratada a $180^{\circ} \mathrm{C}$ $(3,29 \mathrm{MPa})$.

As juntas de madeira de Eucalyptus pellita tratada a $180^{\circ} \mathrm{C}$ coladas com os adesivos resorcinol, RT 80:20 e RT 60:40 apresentaram valores de resistência ao cisalhamento de 6,47, 7,02 e 4,52 MPa, respectivamente. Neste caso, o adesivo RT 60:40 apresentou um desempenho menor que o adesivo RT 80:20 (Tabela 4). Entretanto, todos os adesivos apresentaram valores de resistência ao cisalhamento estatisticamente iguais ao valor da resistência da madeira sólida tratada a $180^{\circ} \mathrm{C}(6,54 \mathrm{MPa})$.

Para o tratamento a $180^{\circ} \mathrm{C}$, o teor de umidade da madeira sólida de Corymbia citriodora foi estatisticamente diferente do teor de umidade das juntas coladas (valor de $\mathrm{Z}=3,61$ ) (Tabela 6). $\mathrm{O}$ valores médios dos postos do teor de umidade da madeira sólida e das juntas coladas no tratamento a $180^{\circ} \mathrm{C}$ foram de 304 e 437 , respectivamente. Isso indica que o teor de umidade das juntas foi maior que o teor de umidade da madeira sólida, o que pode ter afetado os resultados obtidos para a resistência ao cisalhamento de ambas as espécies.

Os valores de resistência ao cisalhamento das juntas de madeira tratada a $200^{\circ} \mathrm{C}$ não apresentaram diferenças estatíticas entre os adesivos utilizados para nenhuma das espécies (Tabela 4). Para a madeira de Corymbia citriodora, os valores de resistência ao cisalhamento das juntas de madeira tratada a $200^{\circ} \mathrm{C}$ coladas com os adesivos resorcinol e RT 60:40 (5,58 e 5,84 $\mathrm{MPa}$, respectivamente) foram superiores ao encontrado para a madeira sólida tratada a $200^{\circ} \mathrm{C}(3,05 \mathrm{MPa})$.

Para o Eucalyptus pellita no tratamento a $200^{\circ} \mathrm{C}$, as juntas coladas com os adesivos resorcinol, RT 80:20 e RT 60:40 apresentaram valores de resistência ao cisalhamento de 5,53, 5,14 e 6,12 MPa, respectivamente. Esses valores foram estatisticamente iguais entre si e quando comparados ao valor de resistência da madeira sólida tratada a $200^{\circ} \mathrm{C}(5,17 \mathrm{MPa})$. 
Não foram observadas diferenças significativas de densidade e de teor de umidade entre as juntas coladas e as madeiras sólidas tratadas a $200^{\circ} \mathrm{C}$ (Tabela 6), mostrando que ambas as propriedades físicas não afetaram os resultados de resistência ao cisalhamento.

Quando compara-se as juntas de madeira não tratada e tratada termicamente para a madeira de Eucalyptus pellita, observa-se que os tratamentos térmicos reduziram drasticamente a resistência ao cisalhamento, independente do adesivo utilizado (Tabela 4).

Para a madeira de Corymbia citriodora, os tratamentos térmicos reduziram a resistência ao cisalhamento das juntas coladas para todos os adesivos quando comparadas às juntas de madeira não tratadas e coladas com os adesivos resorcinol e RT 80:20. As juntas de madeira de Corymbia citriodora não tratada e colada com o adesivo RT 60:40 apresentou uma resistência ao cisalhamento estatisticamente igual ao das juntas de madeira tratadas em ambas as temperaturas (Tabela 4 e Figura 5).

O adesivo RT 80:20 é o mais indicado para as juntas de madeira de Corymbia citriodora e Eucalyptus pellita tratadas e não tratadas termicamente já que apresentou um desempenho melhor ou igual ao adesivo resorcinol. Além disso, a substituição do resorcinol pelo tanino é economicamente vantajosa (GRIGSBI; WARNES, 2004).

\section{Porcentagem de falhas na madeira}

A Tabela 7 apresenta os valores médios da porcentagem de falhas na madeira, do ângulo de orientação dos anéis de crescimento em relação à superfície de colagem e da porosidade da madeira.

Tabela 7. Médias da porcentagem de falhas na madeira, ângulo e porosidade das madeiras de Corymbia citriodora e Eucalyptus pellita não tratadas e tratadas termicamente.

Table 7. Means of wood failure percentage, angle and porosity of the untreated and heat treated Corymbia citriodora and Eucalyptus pellita woods.

\begin{tabular}{|c|c|c|c|c|c|c|c|}
\hline \multirow{2}{*}{ Temperatura $\left({ }^{\circ} \mathrm{C}\right)$} & \multirow{2}{*}{ Adesivo } & \multicolumn{2}{|c|}{ Falhas na madeira (\%) } & \multicolumn{2}{|c|}{ Ângulo $\left({ }^{\circ}\right)$} & \multicolumn{2}{|c|}{ Porosidade (\%) } \\
\hline & & Cc & Ep & Cc & Ep & Cc & Ep \\
\hline \multirow{3}{*}{ Controle } & $\mathrm{R}$ & $\begin{array}{c}34,75 \\
(19,42)\end{array}$ & $\begin{array}{c}51,25 \\
(26,52)\end{array}$ & $\begin{array}{c}33,20 \\
(27,78)\end{array}$ & $\begin{array}{c}95,78 \\
(24,32)\end{array}$ & $\begin{array}{l}36,68 \\
(3,08)\end{array}$ & $\begin{array}{l}42,46 \\
(2,25)\end{array}$ \\
\hline & RT 80:20 & $\begin{array}{c}39,58 \\
(27,91)\end{array}$ & $\begin{array}{c}47,91 \\
(30,98) \\
\end{array}$ & $\begin{array}{c}105,20 \\
(3,68) \\
\end{array}$ & $\begin{array}{c}71,94 \\
(16,91) \\
\end{array}$ & $\begin{array}{l}33,04 \\
(2,68) \\
\end{array}$ & $\begin{array}{l}44,33 \\
(2,23) \\
\end{array}$ \\
\hline & RT 60:40 & $\begin{array}{c}65,00 \\
(25,43) \\
\end{array}$ & $\begin{array}{c}44,75 \\
(24,78) \\
\end{array}$ & $\begin{array}{c}124,77 \\
(46,45)\end{array}$ & $\begin{array}{r}127,70 \\
(30,48) \\
\end{array}$ & $\begin{array}{l}32,00 \\
(2,33) \\
\end{array}$ & $\begin{array}{l}43,17 \\
(3,77) \\
\end{array}$ \\
\hline \multirow{3}{*}{180} & $\mathrm{R}$ & $\begin{array}{c}79,53 \\
(10,75)\end{array}$ & $\begin{array}{l}65,66^{*} \\
(32,12)\end{array}$ & $\begin{array}{c}171,93 \\
(6,63)\end{array}$ & $\begin{array}{c}90,94 \\
(73,53)\end{array}$ & $\begin{array}{l}46,88 \\
(5,42)\end{array}$ & $\begin{array}{l}51,74 \\
(4,53)\end{array}$ \\
\hline & RT 80:20 & $\begin{array}{c}64,38^{*} \\
(30,51)\end{array}$ & $\begin{array}{c}82,83 \\
(19,36)\end{array}$ & $\begin{array}{c}49,10 \\
(27,66)\end{array}$ & $\begin{array}{c}61,25 \\
(48,71)\end{array}$ & $\begin{array}{l}48,95 \\
(5,48)\end{array}$ & $\begin{array}{l}50,38 \\
(2,98)\end{array}$ \\
\hline & RT 60:40 & $\begin{array}{c}79,87 \\
(11,99) \\
\end{array}$ & $\begin{array}{l}95,36 \\
(4,78)\end{array}$ & $\begin{array}{l}122,30 \\
(44,48)\end{array}$ & $\begin{array}{c}40,77 \\
(35,24)\end{array}$ & $\begin{array}{l}50,35 \\
(4,54) \\
\end{array}$ & $\begin{array}{l}53,44 \\
(2,29) \\
\end{array}$ \\
\hline \multirow{3}{*}{200} & $\mathrm{R}$ & $\begin{array}{c}42,37 \\
(23,12)\end{array}$ & $\begin{array}{l}92,31 \\
(6,46)\end{array}$ & $\begin{array}{l}142,75 \\
(30,18)\end{array}$ & $\begin{array}{c}48,87 \\
(58,09)\end{array}$ & $\begin{array}{l}45,27 \\
(2,19)\end{array}$ & $\begin{array}{l}50,90 \\
(2,50)\end{array}$ \\
\hline & RT 80:20 & $\begin{array}{c}77,13 \\
(12,13) \\
\end{array}$ & $\begin{array}{l}93,46 \\
(6,71) \\
\end{array}$ & $\begin{array}{c}165,70 \\
(6,32) \\
\end{array}$ & $\begin{array}{c}46,85 \\
(12,41) \\
\end{array}$ & $\begin{array}{l}52,66 \\
(1,10) \\
\end{array}$ & $\begin{array}{l}51,96 \\
(1,62)\end{array}$ \\
\hline & RT 60:40 & $\begin{array}{l}94,12 \\
(5,13) \\
\end{array}$ & $\begin{array}{l}96,77 \\
(3,80) \\
\end{array}$ & $\begin{array}{r}104,10 \\
(16,42)\end{array}$ & $\begin{array}{c}50,00 \\
(40,02)\end{array}$ & $\begin{array}{l}50,56 \\
(1,65) \\
\end{array}$ & $\begin{array}{l}53,10 \\
(1,85) \\
\end{array}$ \\
\hline
\end{tabular}

R: resorcinol. RT: resorcinol-tanino. Cc: Corymbia citriodora. Ep: Eucalyptus pellita. Médias sublinhadas indicam que estas atingiram os valores mínimos requeridos pela norma ASTM D $3110-94$. * Apresentam mais de $10 \%$ de amostras com menos de $30 \%$ de falha na madeira.

A madeira de Eucalyptus pellita não tratada não atendeu o valor médio mínino de falha na madeira exigido pela norma ASTM D 3110-94, o qual é de 60\%. O mesmo foi observado para a madeira de Corymbia citriodora não tratada, com exceção das juntas coladas com o adesivo RT 60:40, cuja porcentagem de falha foi de $65 \%$ (Figura 6). Isso deve-se provavelmente à dificuldade de penetração do adesivo na estrutura das madeiras, as quais apresentam altas densidades e consequentemente baixa porosidade. 

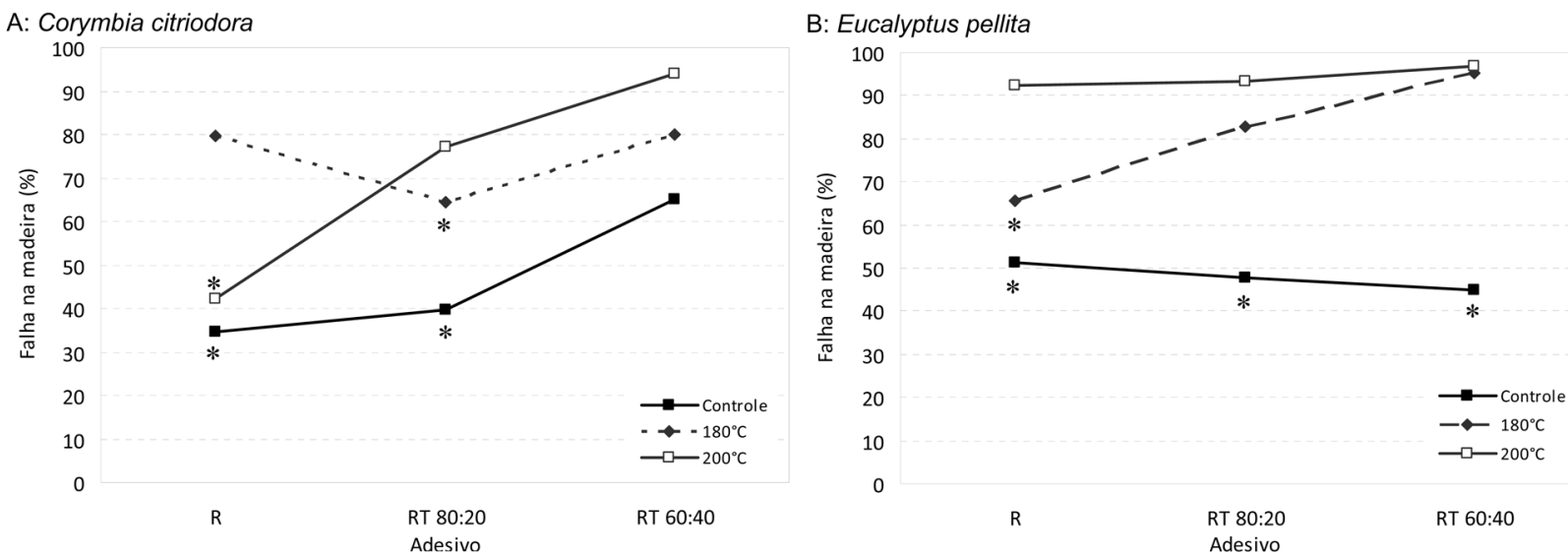

Figura 6. Porcentagem de falhas na madeira após o ensaio de cisalhamento das juntas coladas para as madeiras de Corymbia citriodora e Eucalyptus pellita não tratadas e tratadas termicamente. R: resorcinol. RT: resorcinol-tanino. * Não atende os requisitos exigidos pela norma ASTM D 3110-94.

Figure 6. Percentage of wood failure after shear strength of the glued joints of the untreated and heat treated Corymbia citriodora and Eucalyptus pellita woods. R: resorcinol. RT: resorcinol-tannin. * Did not reach the requeriments of the ASTM D 3110-94 standard.

Para as madeiras tratadas termicamente, a porcentagem de falhas teve um comportamento diferente da madeira não tratada. Para o tratamento a $180^{\circ} \mathrm{C}$, a porcentagem de falhas na madeira de Corymbia citriodora foi de 79,53, 64,38 e 79,87\% para os adesivos resorcinol, RT 80:20 e RT 60:40, respectivamente, enquanto que para a madeira de Eucalyptus pellita, esses valores foram de 65,66, 82,83 e 95,36\% para os mesmos respectivos adesivos. Todos esses valores atenderam à norma ASTM D 3110-94 quanto ao valor médio mínimo de 60\%. Entretanto, a madeira de Corymbia citriodora colada com RT 80:20 e a madeira de Eucalyptus pellita colada com resorcinol, ambas tratadas à $180^{\circ} \mathrm{C}$, apresentaram mais de $10 \%$ de amostras com menos de 30\% de falhas na madeira, o que não atende a exigência da norma ASTM D 3110-94 (Figura 6).

Para o tratamento a $200^{\circ} \mathrm{C}$, somente a madeira de Corymbia citriodora colada com resorcinol não atendeu os valores mínimos estabelecidos pela norma ASTM D 3110-94 (Figura 6). Estes resultados indicam que os tratamentos térmicos aumentaram a porosidade da madeira, facilitando a penetração do adesivo, o que resultou na maior porcentagem de falhas na madeira. Esse comportamento também foi observado por outros autores. Mirzaei et al. (2012) encontraram um aumento no percentual de falhas da madeira de Fagus orientalis tratada termicamente e colada com os adeisvos uréia-formaldeído e epóxi. O mesmo foi observado por Poncsák et al. (2007) para as madeiras de Pinus sylvestris e Liriodendron tulipifera tratadas termicamente e coladas com os adesivos fenol-resorcinol-formaldeído e poliuretano, respectivamente. O aumento da porcentagem de falhas também pode ser explicado pela perda de resistência da madeira tratada termicamente, a qual tem sido comprovada por vários autores (GHALEHNO; NAZERIAN, 2011; GUNDUZ et al., 2009; KOL et al., 2009).

Os resultados deste estudo também corroboram com aqueles encontrados por Pincelli et al. (2002) ao estudar o efeito do tratamento térmico na resistência ao cisalhamento e no percentual de falhas da madeira de Eucalyptus saligna tratada a 120,140, 160 e $180^{\circ} \mathrm{C}$ e coladas com os adesivos fenol-resorcinol-fomaldeído, uréia-formaldeído e acetato polivinílico. Esses autores afirmam que o tratamento térmico causa modificações na resistência mecânica da madeira, mas não na interface madeira-adesivo.

\section{Análises de correlação}

A Tabela 8 apresenta as análises de correlação entre a resistência ao cisalhamento e as propriedades físicas (densidade e teor de umidade), a porcentagem de falha na madeira, o ângulo de orientação dos anéis de crescimento em relação à superfície de colagem, a porosidade e o pH da madeira.

A resistência ao cisalhamento apresentou uma correlação positiva significativa com a densidade ( $r$ 
$=0,40)$, o teor de umidade $(r=0,73)$ e o pH da madeira $(r=0,55)$, sendo o teor de umidade o fator que apresentou a maior correlação com a resistência das madeiras estudadas. Estudos realizados por Kretschmann e Green (1996) sobre o efeito do teor de umidade nas propriedades mecânicas da madeira, mostraram que a resistência ao cisalhamento aumenta com a redução do teor de umidade até $4 \%$, o que contradiz com os resultados encontrados neste estudo. Isso ocorreu porque o menor teor de umidade das madeiras está associado às modificações químicas causadas pelo tratamento térmico.

Tabela 8. Análises de correlação entre a resistência ao cisalhamento e as propriedades físicas, falha, ângulo, porosidade e $\mathrm{pH}$ da madeira.

Table 8. Correlation analysis between shear strength and wood plysical properties, failure, angle, porosity and pH.

\begin{tabular}{|c|c|c|c|c|c|c|c|}
\hline Variáveis & fv & DENS $_{\mathrm{fv}}$ & $T_{U_{f v}}$ & Falha & Ângulo & Porosidade & $\mathrm{pH}_{\text {madeira }}$ \\
\hline$f v$ & 1 & & & & & & \\
\hline DENS $_{f v}$ & $0,40^{*}$ & 1 & & & & & \\
\hline$T_{\mathrm{fv}_{\mathrm{v}}}$ & $0,73^{*}$ & $0,51^{*}$ & 1 & & & & \\
\hline Falha & $-0,54^{*}$ & $-0,47^{*}$ & $-0,53^{*}$ & 1 & & & \\
\hline Ângulo & $-0,07$ & $0,19^{*}$ & $-0,02$ & $-0,19^{*}$ & 1 & & \\
\hline Porosidade & $-0,57^{*}$ & $-0,94^{*}$ & $-0,79^{*}$ & $0,53^{*}$ & $-0,13$ & 1 & \\
\hline $\mathrm{pH}_{\text {madeira }}$ & $0,55^{*}$ & $0,64^{*}$ & $0,81^{*}$ & $-0,49^{*}$ & $-0,05$ & $-0,80^{*}$ & 1 \\
\hline
\end{tabular}

$\mathrm{f}_{\mathrm{v}}$ : resistência ao cisalhamento na compressão paralela às fibras. $D E N S_{\mathrm{fv}}$ : densidade das juntas de madeira. $\mathrm{TU}_{\mathrm{fv}}$ : teor de umidade das juntas. *Significativo à $95 \%$ de probabilidade.

$\mathrm{O}$ pH da madeira teve uma forte correlação com as propriedades físicas das juntas de madeira (DENS $_{\mathrm{fv}}$ e TU $\left.\mathrm{fv}_{\mathrm{fv}}\right)$ e afetou significativamente a resistência ao cisalhamento $(r=0,55)$ e a porcentagem de falhas na madeira $(r=-0,49)$. A forte correlação entre o $\mathrm{pH}$ da madeira e o teor de umidade $(r=$ $0,81)$ mostrou que o teor de umidade diminuiu à medida que o $\mathrm{pH}$ da madeira diminuiu. Isso pode ser explicado pela degradação das hemiceluloses durante o tratamento térmico, as quais são os polímeros mais higroscópicos da parede celular. A degradação desses polímeros reduz a higroscopicidade da madeira, o que provoca a redução no teor de umidade de equilíbrio, entretanto nesse processo de degradação ocorre também a formação de ácidos acético e fórmico que aumentam a acidez da madeira. Os ácidos formados na degradação das hemiceluloses agem como um catalisador para a despolimerização das microfibrilas de celulose, quebrando a celulose em cadeias mais curtas. Além disso, após o tratamento térmico ocorre reticulação entre a lignina e os polímeros resultantes da degradação térmica, formando assim um complexo polimérico modificado (FIGUEROA; MORAES, 2009; FTA, 2003). As modificações químicas ocasionadas na celulose e na lignina podem explicar a redução na resistência da madeira, já que esses polímeros são os maiores responsáveis pela sua resistência mecânica (FPL, 2010).

A porcentagem de falha apresentou uma correlação negativa com a resistência ao cisalhamento $(r=-0,54)$, a densidade das juntas $(r=-0,47)$, o teor de umidade das juntas $(r=-0,53)$ e o ângulo $(r=-0,19)$ (Tabela 8). Observa-se que novamente o teor de umidade foi o fator que apresentou a correlação mais alta com a porcentagem de falhas. O ângulo de orientação dos anéis com relação à superfície de colagem apresentou uma fraca correlação com a porcentagem de falhas das madeiras estudadas. De acordo com o FPL (2010), a penetração do adesivo depende da permeabilidade e varia de acordo com a orientação da grã sendo maior no sentido longitudinal que no sentido perpendicular. Entretanto, as diferenças de permeabilidade entre as faces radial e tangencial são menores e dependem das características anatômicas da espécie.

A porosidade da madeira também apresentou uma correlação com a resistência ao cisalhamento e a porcentagem de falhas na madeira. Na Tabela 8, observa-se que a correlação entre porosidade e resistência ao cisalhamento é moderada $(r=-0,57)$ quando as duas espécies são incluídas na análise. Entretanto, quando esta correlação é observada para cada espécie individualmente, nota-se que esta correlação torna-se mais forte, com coeficientes de -0,609 e -0,787 para as madeiras de Corymbia citriodora e Eucalyptus pellita, respectivamente (Figura 7). 

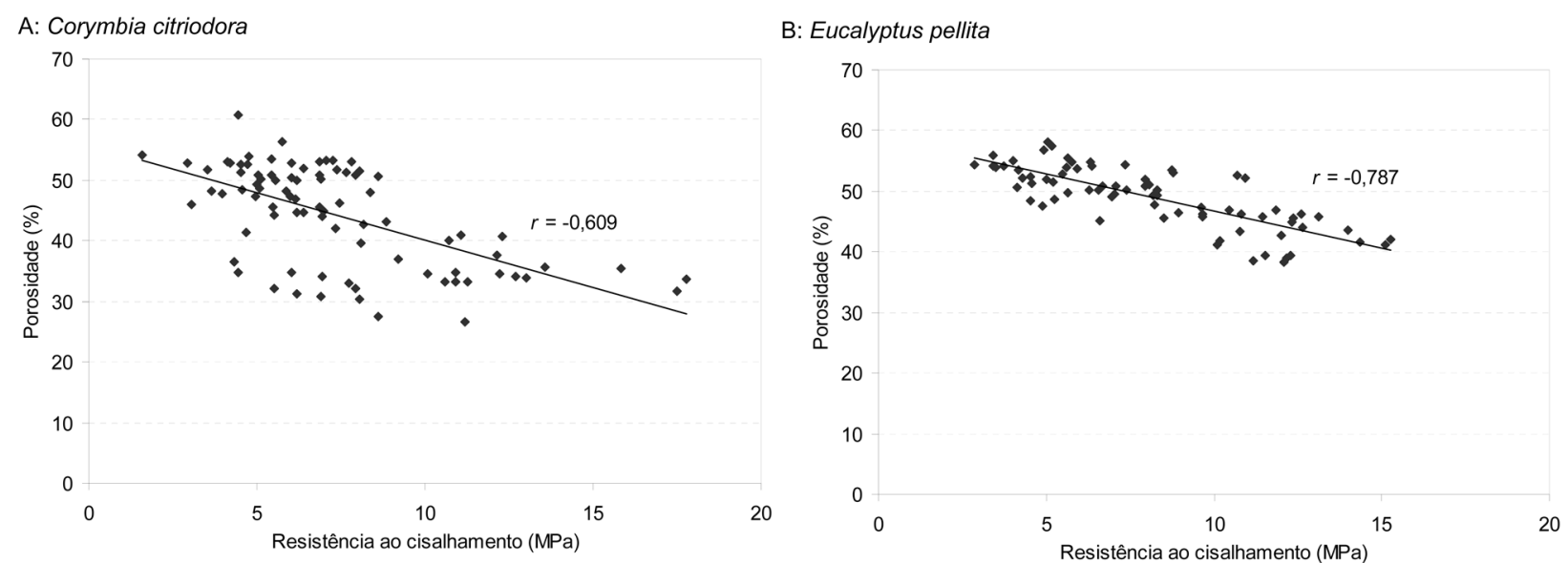

Figura 7. Correlação entre a porosidade da madeira e a resistência ao cisalhamento das juntas de madeira de Corymbia citriodora e Eucalyptus pellita.

Figure 7. Correlation between porosity and shear strength of the glued joints of the Corymbia citriodora and Eucalyptus pellita woods.

A porcentagem de falhas apresentou uma correlação positiva com a porosidade $(r=0,53)$, isto é, a porcentagem de falhas na madeira aumentou com o aumento da porosidade, indicando uma maior penetração do adesivo. Os resultados apresentados na Tabela 7 mostram que o tratamento térmico aumentou a porosidade da madeira, facilitando assim a penetração do adesivo na madeira. A Figura 8 mostra a correlação entre porosidade e porcentagem de falhas na madeira para as espécies de Corymbia citriodora e Eucalyptus pellita, individualmente.
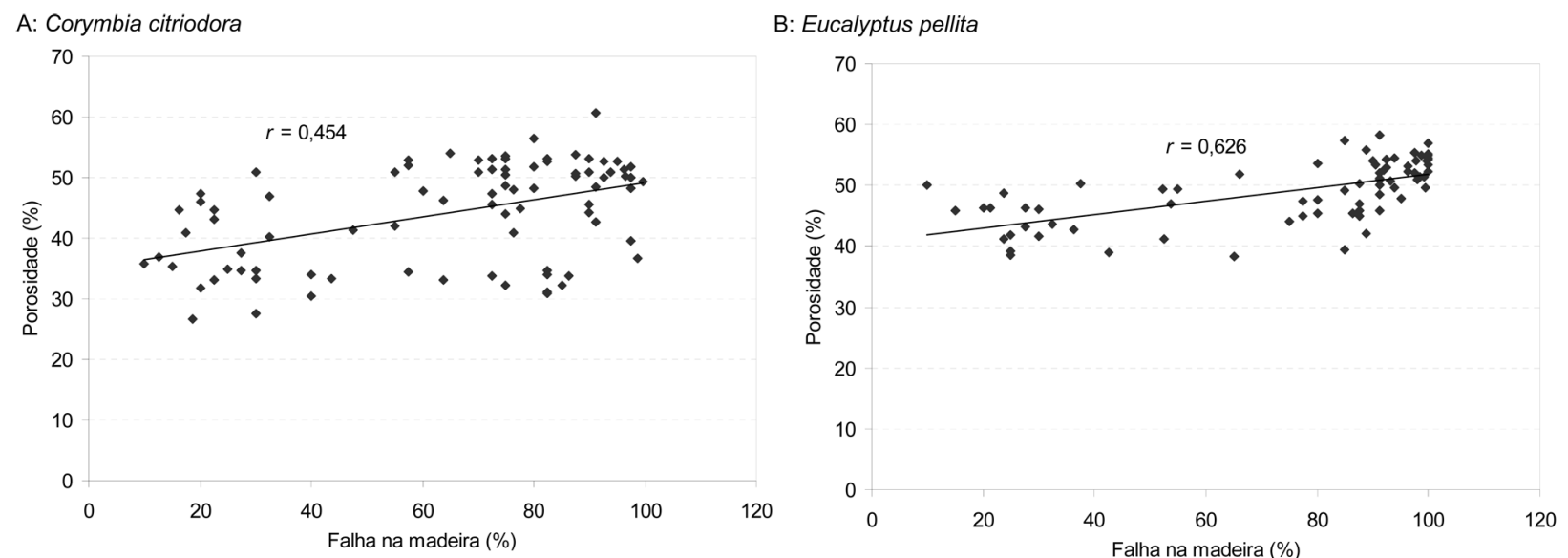

Figura 8. Correlação entre a porosidade da madeira e a porcentagem de falhas das madeiras de Corymbia citriodora e Eucalyptus pellita.

Figure 8. Correlation between porosity and wood failure of the Corymbia citriodora and Eucalyptus pellita woods.

Os resultados de porosidade das madeiras de Corymbia citriodora e Eucalyptus pellita tratadas termicamente corroboram com as observações feitas por Awoyemi e Jones (2011); Boonstra et al. (2006). Awoyemi e Jones (2011) estudaram o efeito do tratamento a $220^{\circ} \mathrm{C}$ durante 1 e 2 horas na anatomia da madeira de Thuja plicata (conífera) e verificaram que, após o tratamento, a parede dos traqueídeos, o tecido dos raios e as pontoações areoladas aspiradas foram degradadas. A degradação das pontoações ampliou as aberturas nas paredes celulares. Esses fatores contribuiram para o aumento do volume de vazios ou porosidade e consequentemente para a redução da densidade da madeira. Boonstra et al. (2006), ao avaliar o efeito do tratamento térmico na anatomia das madeiras de Fagus sylvatica, Populus sp, Simaruba amara, Betula pendula/pubescense, Alnus glutinosa/incana e Fraxinus excelsior, observaram que as madeiras apresentaram células colapsadas e fibras deformadas após o tratamento. As madeiras apresentaram rompimentos evidenciados por rachaduras próximas aos raios e pequenas fissuras nos traqueídeos.

Nas Figuras 7 e 8, observa-se que os maiores coeficientes de correlação da porosidade com a resistência ao cisalhamento e a porcentagem de falhas foram encontrados para a madeira de Eu- 
calyptus pellita, a qual, segundo Nunes (2012) apresenta maior perda de massa após o tratamento térmico. A perda de massa está associada à perda de água, volatilização dos extrativos e degradação da parede celular (AWOYEMI; JONES, 2011; BRITO et al., 2008; GUEDIRA, 1988).

\section{CONCLUSÕES}

A resistência ao cisalhamento da madeira sólida e das juntas coladas de ambas as espécies estudadas foram severamente afetadas pelo tratamento térmico.

$\mathrm{O}$ adesivo resorcinol-tanino 80:20 apresentou um desempenho melhor ou igual ao resorcinol.

As juntas de madeiras tratadas termicamente apresentaram altas porcentagens de falha devido à perda de resistência da madeira, maior porosidade e maior penetração do adesivo.

A acidez da madeira tratada termicamente afetou a resistência ao cisalhamento e apresentou uma forte correlação com o teor de umidade de equilíbrio devido à degradação das hemiceluloses.

As temperaturas de 180 e $200^{\circ} \mathrm{C}$ são extremamente severas para a resistência mecânica das madeiras de Corymbia citriodora e Eucalyptus pellita nas condições estudadas.

\section{REFERÊNCIAS BIBLIOGRÁFICAS}

ASTM - AMERICAN SOCIETY FOR TESTING AND MATERIALS. D 143: Standard methods of testing small clear specimens of timber. 1994a. p. 24-65.

ASTM - AMERICAN SOCIETY FOR TESTING AND MATERIALS. D 905: Standard test method for strength properties of adhesive bonds in shear by compression loading. 1994b. p. 20-26.

ASTM - AMERICAN SOCIETY FOR TESTING AND MATERIALS. D 2395: Standard test methods for specific gravity of wood and wood-based materials. 1999. p. 350-357.

ASTM - AMERICAN SOCIETY FOR TESTING AND MATERIALS. D 3110: Standard specification for adhesives used in nonstructural glued lumber products. 1994c. p. 184-192.

AWOYEMI, L.; JONES, I. P. Anatomical explanations for the changes in properties of western red cedar (Thuja plicata) wood during heat treatment. Wood Science and Technology, New York, v. 45, n. 2, p. 261-267, 2011.

BOONSTRA, M. J.; RIJSDIJK, J. F.; SANDER, C.; KEGEL, E.; TJEERDSMA, B.; MILITZ, H.; VAN ACKER, J.; STEVENS, M. Microstrucural and physical aspects of heat treated wood; Part 2. Hardwoods. Maderas, Ciencia y tecnología, Concepción, v. 8, n. 3, p. 209-218, 2006.

BOONSTRA, M. J.; VAN ACKER, J.; KEGEL, E.; STEVENS, M. Optimisation of a two-stage heat treatment process: durability aspects. Wood Science and Technology, New York, v. 41, n. 1, p. 31-57, 2007.

BRITO, J. O.; SILVA, F. G.; LEÃO, M. M.; ALMEIDA G. Chemical composition changes in eucalyptus and pinus woods submitted to heat treatment. Bioresource Technology, Essex, v. 99, n. 8, p. 8545-8548, 2008.

COSTA, M. M.; COLODETTE, J. L.; GOMIDE, J. L.; FOELKEL, C. E. B. Avaliação preliminar do potencial de quatro madeiras de eucalipto na produção de polpa solúvel branqueada pela sequência $O A(Z Q) P^{1}$. Revista Árvore, Viçosa, v. 21, n. 3, p. 385-392, 1997.

DOMBRO, D. B. Eucalyptus pellita: Amazonia Reforestation's red mahogany. Planeta Verde Reforestación S.A., 2010. 8 p.

FIGUEROA, M. J. M.; MORAES, P. D. Comportamento da madeira a temperaturas elevadas. Ambiente Construído, Porto Alegre, v. 9, n. 4, p. 157-174, 2009.

FPL - FOREST PRODUCTS LABORATORY. Wood handbook - Wood as an engineering material. Madison: USDA Forest Service, 2010. 508 p. (FPL General Technical Report, 190) 
Nunes et al. - Qualidade de adesão das madeiras de Corymbia citriodora e Eucalyptus pellita tratadas termicamente

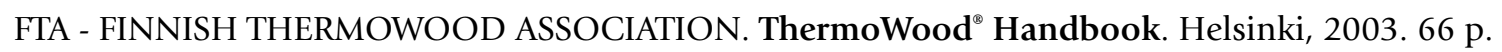

GHALEHNO, M. D.; NAZERIAN, M. Changes in the physical and mechanical properties of Iranian hornbeam wood (Carpinus betulus) with heat treatment. European Journal of Scientific Research, v. 51, n. 4, p. 490-498, 2011.

GUEDIRA, F. Pyrolyse lente de la biomasse: comportement comparé des tourteux d'olives, de la bagasse de canne à sucre et de la sciure de bois (Pin maritime). 1988. 122 p. Tese (Doutorado) - Université Mohamed V, Maroc, 1988.

GUNDUZ, G.; KORKUT, S.; AYDEMIR, D.; BEKAR, Í. The density, compression strength and surface hardness of the heat treated hornbeam (Carpinus betulus) wood. Maderas. Ciencia y Tecnología, Concepción, v. 11, n. 1, p. 61-70, 2009.

IPT - INSTITUTO DE PESQUISAS TECNOLÓGICAS DO ESTADO DE SÃO PAULO. Sistema de Informações de Madeiras Brasileiras. São Paulo: IPT, 1989. 291 p. Relatório n. 27078.

KOL, H. S.; OZBAY, G.; ALTUN, S. Shear strength of heat-treated tali (Erytrhophleum ivorense) and iroko (Chlorophora excelsa) woods, bonded with various adhesives. BioResources, Raleigh, v. 4, n. 4, p. 1545-1554, 2009.

KRETSCHMANN, D. E.; GREEN, D. W. Modeling moisture content-mechanical property relationships for clear southern pine. Wood and Fiber Science, Madison, v. 28, n. 3, p. 320-337, 1996.

MACLEAN, J. D. Preservative treatment of wood by pressure methods. Washington: USDA Forest Service, 1952. 160 p. (Agriculture Handbook, 40)

MIRZAEI, G.; MOHEBBY, B.; TASOOJI, M. The effect of hydrothermal treatment on bond shear strength of beech wood. European Journal of Wood and Wood Products, Berlin, v. 70, n. 5, p. 705-709, 2012.

NUNES, C. S. Propriedades tecnológicas e qualidade de adesão de madeiras de Corymbia citriodora e Eucalyptus pellita termorretificadas. 2012. 56 p. Dissertação (Mestrado em Ciências Ambientais e Florestais) - Universidade Federal Rural do Rio de Janeiro, Seropédica, 2012.

PINCELLI, A. L. P. S. M.; BRITO, J. O.; CORRENTE, J. E. Avaliação da termorretificação sobre a colagem na madeira de Eucalyptus saligna e Pinus caribaea var. hondurensis. Scientia Forestalis, Piracicaba, n. 61, p. 122132, 2002.

PONCSÁK, S.; SHI, S. Q.; KOCAEFE, D.; MILLER, G. Effect of thermal treatment of wood lumbers on their adhesive bond strength and durability. Journal of Adhesion Science and Technology, v. 21, n. 8, p. 745-754, 2007.

ROWELL, R. M. (Ed.) Handbook of wood chemistry and wood composites. Boca Raton: CRC Press, 2005.

SERNEK, M.; BOONSTRA, M.; PIZZI, A.; DESPRES, A.; GÉRARDIN, P. Bonding performance of heat treated wood with structural adhesives. Holz als Roh-und Werkstoff, Berlin, v. 66, n. 3, p. 173-180, 2008.

WILLIAMS, R. S. Finishing of Wood. In: FPL - FOREST PRODUCTS LABORATORY. Wood handbook - Wood as an engineering material. Madison: USDA Forest Service, 2010. Cap. 16. (FPL General Technical Report, 190).

Recebido em 08/10/2014

Aceito para publicação em 30/07/2015 